Fecha de recepción: diciembre 2017

Fecha de aceptación: marzo 2018

Versión final: julio 2019

\section{El paisaje urbano informal interpelado desde el arte}

María Noel Luna *

Resumen: El arte urbano actual no sólo pretende entablar un diálogo con la sociedad sino que propone transformar la ciudad. Un caso modélico sobre la utilización del arte como interventor del paisaje urbano, el cual se presenta en este escrito, es el proyecto Favela-painting, experiencia de arte colectivo que ha potenciado y ampliado las potestades del arte urbano, vinculando métodos y expresiones del campo artístico con objetivos de mejora urbana.

Motivados por la desigualdad social, dos artistas holandeses deciden reinterpretar el lienzo, encontrando en las fachadas precarias de las viviendas populares un posible medio de expresión. El análisis de esta experiencia, desde el enfoque de la planificación urbana, interpela el espacio informal a través del arte, dado que las mejoras logradas sobre al paisaje urbano y la calidad constructiva de la vivienda popular son notables.

La conflictividad social se aborda de manera alternativa empoderando a la población con el arte como vehículo de apropiación, cooperación, capacitación y autogestión. Esta iniciativa ha sido coincidente con otras actuaciones sobre la informalidad urbana promovidas desde el estado. Programas de mejora barrial y de seguridad se superponen con el caso en cuestión, proponiendo en la mezcla de estos campos nuevas formas de relación entre el arte y la política.

Palabras clave: Arte urbano - cooperación - desigualdad - intervención - paisaje urbano.

[Resúmenes en inglés y portugués en las páginas 43-44]

${ }^{*}$ Arquitecta, Magíster en Planificación Urbana y Regional (FADU-UBA). Investigador formado, Proyecto Ubacyt 2017-2019 “Gestión Urbana Contemporánea”. Directora de Proyecto de Investigación en el marco del Programa de Jóvenes Investigadores (JIN) 20172019: "Proyecto Urbano e Infraestructura Urbana en América Latina. Su aplicación orientada al abordaje de la fragmentación y exclusión socio-territorial". Investigador, docente y consultor FADU-UBA desde 2009. Prof. Adjunto de la materia Gestión Urbana Contemporánea (GUC), Cátedra Szajnberg. Docente en la materia de Planificación Urbana (PU), Cátedra Giglio. 


\section{Introducción}

El presente escrito intentará conocer y comprender algunos conceptos básicos de la sociología de la cultura y del arte, especialmente aquellos referidos a las prácticas estéticopolíticas que promueven procesos transformadores. Fin que se aborda desde un proyecto de investigación en curso, el cual enmarcado en el área disciplinar de la planificación urbana se adentra específicamente en los procesos proyectuales capaces de transformar una territorialidad.

En esta intención de transformación, se detecta que a partir de la sociología del arte, se ha permitido alcanzar logros de intervención que complementan los alcances de las iniciativas implementadas desde las políticas públicas para la mejora urbana de las áreas de informalidad.

El tema presentado posee pertinencia de investigación en el marco del Programa de Jóvenes Investigadores (JIN) de la SI-FADU-UBA", con un proyecto denominado: "Proyecto Urbano e Infraestructura Urbana en América Latina. Su aplicación orientada al abordaje de la fragmentación y exclusión socio-territorial"' ${ }^{2}$. Donde el recorte temporal que da marco contextual es el primer quindenio del siglo XXI. La unidad de análisis principal es un instrumento urbanístico de desarrollo urbano, identificado conceptual y operacionalmente como Proyecto Urbano Integral (PUI). A través del estudio de esta herramienta se detecta que su actuación en áreas de informalidad como acción planificada, en materia de intervención urbana, aún devela contradicciones entre las voluntades técnicos-políticas de la planificación y los recursos con los que cuenta, de acuerdo al modelo de desarrollo de inserción.

Un aspecto clave que visibiliza estas discrepancias en los procesos de planificación inclusiva es la dificultad, y en otras ocasiones, la incapacidad de abordar eficientemente el espacio privado informal que caracteriza al hábitat popular. Las acciones se direccionan en primera medida a transformar el espacio público, irradiando mejoras hacia el espacio privado. Por lo tanto las mejoras en términos de acceso al hábitat se dan de forma cualitativa y no cuantitativa. Esta medida reconoce las limitaciones que la política pública habitacional tradicional posee en contextos de actualidad y mediante un enfoque alternativo encara la demanda de acceso al espacio residencial económico.

El PUI, es entonces, la resultante de un pensamiento crítico urbano que propone ante la problemática creciente de la informalidad, una solución posible, encarnada bajo una modalidad de transformación con objetivos de inclusión.

A diferencia de experiencias anteriores del Proyecto Urbano (PU), el cual construía su lógica proyectual desde la obsolescencia urbana, el PUI enfoca su lógica desde las carencias que se evidencian de acuerdo a tres dimensiones territoriales:

- La dimensión física: Reconoce la problemática de los bajos estándares habitacionales, la falta de infraestructuras básicas, la ausencia de espacios públicos y la degradación ambiental. - La dimensión social: Evidencia pobreza y falta de oportunidades, sumado a un entorno de alta conflictividad social.

- La dimensión institucional: Se ve reflejada por la ausencia del estado que se manifiesta en la falta de control de los procesos de ocupación del territorio. 
Los PUI son políticas públicas urbanas de promoción y postulación que se caracterizan por poseer resultados concretos y tangibles sobre el territorio, son transformadores de la realidad. Ante esta cuestión, y dado que en la región Sudamericana existe aporte empírico, conviene considerar los impactos que estas intervenciones generan, dado que en muchas ocasiones, son estas mismas políticas las que refuerzan la desigualdad y la fragmentación de los territorios (Cappuccio y Mignaqui, 2015).

La región Sudamericana en el último quindenio ha sido fuente de aporte empírico de esta modalidad de intervención desde las políticas públicas, dando sustento a una metodología de investigación empiricista abierta y exploratoria, que permite adquirir gran parte del conocimiento asociando hechos a cuestiones teórico-metodológicas.

El encuadre epistemológico, ante la temática de la inclusión propiciada a través de la concreción de los PUI, refiere al enfoque del "Realismo Crítico" (corriente del pospositivismo) donde la realidad existe en su contexto, y donde la búsqueda de la transformación del objeto de estudio o bien del contexto, es materia de indagación.

A modo de cierre de esta introducción se nombran los referentes conceptuales principales, y las razones por las cuales se los considera.

- Heidegger ${ }^{3}$ - La necesidad interpretativa y ontológica de la realidad, se observa lo que inquieta, se comprende y racionaliza desde su marco de inserción contextual y circunstancial existencial (Dasein).

- Lefebvre $^{4}$ - El ideario del "Derecho a la Ciudad" y la comprensión de las dinámicas urbanas en relación al modo de producción capitalista, es su gran aporte. Que en épocas subsiguientes a 1968, es retomado y reinterpretado por diversos autores, que perpetuaron con validación contextual, tras la época neoliberal, las formulaciones que Lefebvre esgrimió de manera utópica.

- Habermas ${ }^{5}$ - La "Racionalidad Eficaz", que plantea Jürgen Habermas da cuenta de un enfoque social de la racionalidad instrumental y explica en gran medida la lógica instrumental del PUI. Es una racionalidad instrumental que entrecruza acciones sociales orientadas al éxito.

- UN Hábitat ${ }^{6}$ - De esta modalidad internacional de construcción de agenda, interesa la ampliación de acepciones restrictivas, puntualmente en el tema del hábitat y el derecho al arraigo. Desde el inicio de la proclamación y adscripción global de las agendas, la noción de hábitat se transforma, hasta superar el sentido restrictivo del techo, y se amplía al acceso a la calidad de vida.

Lo antes expuesto da inserción al tema presentado en este escrito y reconoce la capacidad de actuación que la sociedad organizada posee, resaltando la diversidad de actores sociales que en la actualidad pueden promover transformaciones urbanas desde diversos campos disciplinares. Específicamente el caso Favela- painting opera en Brasil en la ciudad de Río de Janeiro en dos favelas de relevancia, la favela de Vila Cruzeiro y la favela de Santa Marta. Su actuación articuló con otras políticas públicas, Brasil desde el año $2000^{7}$ cuenta con un Programa de Urbanización de Asentamientos Populares (PROAP) conocido como Programa Favela-Barrio, promovido por el Gobierno del Estado de Rio de Janeiro. Instrumento Urbanístico que ha recibido financiación del Banco Interamericano de Desarrollo 
para ejecutarse, y el cual se asocia operacional y conceptualmente con la unidad de análisis del proyecto marco de investigación ${ }^{8}$. A su vez con miras a eventos globales, particularmente el mundial de fútbol del año 2014, el cual tuvo sede en este país, se implementó mediante la Secretaria de Seguridad del Estado de Rio de Janeiro, el Programa de Pacificación de las Favelas. Intervención que intentó recuperar de manos de la milicia y de los narcotraficantes estos espacios de ciudad informal. El proyecto se denomino Unidades de Policía Pacificadora (UPP).

Santa Marta fue la primera favela en contar con una comisaria de control policial comunitario, luego se implementó en la calle de entrada a la Vila Cruzerio. En coincidencia con estas acciones de control de la violencia en los enfrentamientos por el dominio del territorio entre narcotraficantes y milicianos, y con los PROAP se llevan a cabo las intervenciones del Favela-painting.

En la actualidad se demuestra que existe una desaceleración de las intervenciones en las áreas de informalidad, las sucesivas crisis políticas coyunturales y económicas de la región Sudamericana plantean nuevos desafíos ante aquellos proyectos que intentan hacer ciudad con calidad de vida. A pesar de ello el Favela-Painting Project plantea su obra de mayor envergadura, pintar una favela completa.

\section{Cuestiones teórico-metodológicas}

A modo de guía y como cuestión teórica-metodológica principal para la interpretación artística del caso Favela-Painting, se toma como referente la acepción de "Mundo del Arte" de Howard S. Becker. Autor que define al mundo del arte desde una arista técnica, despojada de discursos metafóricos y laxos que se basan en corrientes elitistas de consumo del arte, en donde la calidad de la obra es definida por el precio al que se vende. Por el contrario, el mundo del arte es entendido como una actividad cooperativa, organizada a través del conocimiento, y que llevada a cabo mediante convenciones es capaz de producir el tipo de trabajos artísticos que caracterizan al mundo del arte.

Desde un enfoque tautológico Becker plantea una mirada original en torno a la Sociología del Arte, la cual propone ampliar el campo exploratorio sobre las posibilidades en que la gente produce y consume obras de arte. Esta exploración se sustenta en una mirada sociológica, que a partir de la connotación básica del sentido de la ciencia social, profundiza en la comprensión de las cosas sobre las cuales ya existe conciencia (Becker, 2008). En su análisis esquiva el juicio estético y se centra en la dimensión de lo social y organizacional, mediante el estudio de las redes cooperativas que se ven envueltas en el proceso de producción del arte.

La cuestión presentada aporta andamiaje teórico-metodológico desde la sociología del arte, y habilita a dar sentido artístico al proyecto Favela-painting, pues se considera que desde el cooperativismo y la incorporación de convenciones (capacitación) previas, se puede formular un proyecto de arte.

Específicamente la obra del caso presentado se enmarca dentro del campo del arte urbano, medio de expresión que posee una particularidad en el caso indagado, dado que produce su resultado gracias a que utiliza como lienzo un paisaje urbano muy especial en 
su condición geográfica y social. Esta particularidad explica la dimensión que adquiere el lienzo, el cual aborda una escala urbana. Hasta el momento es uno de los casos que mayor envergadura intenta alcanzar.

En referencia a esta característica también radican los alcances de los vínculos cooperativos, dado que solo un artista no sería capaz de realizarlo. De acuerdo a este análisis entra en juego la complejidad del proceso de producción de la obra. La participación del artista en los vínculos cooperativos, junto al reconocimiento de la dependencia de los mismos limita el tipo de arte que puede producir (Becker, 2008). El estilo artístico que se adopta hace referencia al Fauvismo por un lado y al Cubismo por otro. Respectivamente, el primero se ve asociado al uso del color y el juego cromático implementado para llamar la atención; y el segundo se utiliza como método estructural de composición para abordar la morfología urbana de las favelas como lienzo bidimensional. Es en esta fusión de estilos que el colectivo artístico Favela-painting proyecta su obra de mayor alcance, pintar toda la Favela de Vila Cruzeiro en Río de Janeiro. El análisis de las formas del paisaje de la favela posibilitó la aplicación del enfoque estructural del cubismo analítico ${ }^{9}$ como estrategia de composición, donde la obra no es una ventana hacia la naturaleza, sino un objeto que se expresa con rigor en su orden arquitectónico a través de un lenguaje abstracto. Orden que se configuró de forma espontánea a modo de repetición de un fractal (siendo este las viviendas precarias), pero que en la obra, encuentra un orden proyectado integral y unificador.

La ocupación informal del suelo no posee ordenamiento previo ni regulación, es autogestiva, a pesar de esta instancia encuentra en su configuración al margen de la norma, un propio lenguaje para la apropiación del espacio.

Si se analiza la lógica de producción artística de la obra del Favela-Painting (FP), tanto sea desde la práctica urbana en sí misma, o bien desde el estilo de expresión, es clara la identificación con la noción de vanguardia. El proyecto FP visibiliza con sus obras la evolución en el pensamiento científico y político del nuevo siglo. Avance que permitió desde la práctica de la planificación, la incorporación de la informalidad como materia de intervención urbana. De acuerdo al modo de expresión artística que se utilizó, los estilos elegidos responden a diversas técnicas de las vanguardias artísticas.

La noción de vanguardia posee una dual acepción. Es de avanzada por ser punta de lanza e icónico ante la sensibilidad de la época ${ }^{10}$, y es rupturista por rebelarse ante formas artísticas dominantes, instituciones, tradiciones y gustos hegemónicos (Longoni y Davis, 2009: 6). En el FP la lógica vanguardista re-emerge con fuerza, asociada a un paisaje urbano sudamericano que evidencia inequidad en la contemporaneidad, donde hay presencia de situaciones de conmoción cultural, social y política.

El contexto histórico de origen de la corriente de vanguardia se da en la posguerra del primer cuarto del siglo XX, la motivación de los artistas que exploraron esta lógica de producción del arte, se da en función de la búsqueda de un cambio en el pensamiento filosófico y político. Y en alineación con esto, el proyecto FP es fruto de un pensamiento crítico sobre la problemática de la desigualdad y la exclusión social.

Una especificidad que presenta un quiebre, casi un siglo después entre la experiencia contemporánea y la vanguardista de origen, es que en la actualidad no se identifica a la vanguardia con procesos de contracultura, sino que persigue la construcción de una idea artística de ciudad integrada y diversa, al menos desde el discurso colectivo. 
Un análisis comparativo con la Escuela de la Bauhaus de Walter Gropius de 1928, permite asociar la doble acepción de vanguardia que implicó en 2005 actuar de forma planificada en la informalidad. Tal como en esta segunda etapa de la escuela del diseño moderno, la contemporaneidad buscó integrar vanguardias arquitectónicas con vanguardias políticas y sociales, la actuación pensada para la informalidad articula necesariamente con estas dimensiones. Pero lo notorio, tal como ha pasado en la Bauhaus de Gropius, es que si bien se entiende que estas dimensiones se tienen que articular para alcanzar innovaciones y cambios, de acuerdo a pautas de vanguardia (avances o rupturas), no siempre recae sobre el mismo actor social la concreción de la articulación. Dado que esta asociación implica un alto grado de compromiso, que en la mayoría de ocasiones, los actores sociales promotores de transformaciones no desean tranzar (Hervás y Heras, 2015).

Esta cuestión da cuenta que la contemporaneidad abre el juego a multiplicidad de actores sociales, que de forma fragmentada actúan en un mismo recorte territorial dando integración a la transformación.

Existe un consenso entre la voluntad técnico-política para colaborar en la trasformación positiva de los sectores más vulnerables, pero aún se develan contradicciones entre esta voluntad y la capacidad de actuación, dado que los recursos con los que cuentan los estados no son suficientes para intervenir de manera integral y los intereses en juego en muchas ocasiones no quieren entrar en campos de negociación.

Ante esta situación el caso de estudio aportó recursos para la integración, actuando en el espacio privado informal, no legalizándolo, pero si incluyendo mejoras en la calidad del hábitat. Como desafío se encontró con los sucesos cotidianos típicos de la violencia y conflictividad social de las favelas de Río de Janeiro, en donde el narcotráfico y la ausencia del estado se hacen presentes.

\section{El paisaje urbano como entorno socio-político del arte colectivo en la ciudad contemporánea latinoamericana}

Dos componentes principales son utilizados para la transformación: El arte urbano y el paisaje urbano. Desde el punto de vista de la Historia del Arte la ciudad es una obra de arte. Obra configurada desde un campo del conocimiento científico complejo, multidisciplinar y transdisciplinar, conocido como urbanismo, práctica puesta en acción desde 1868 con fines higienistas y de ordenación, que a mediados del siglo XX se convierte en política pública de los estados modernos.

En esta línea de pensamiento el pionero fue el profesor francés Pierre Lavedan ${ }^{11}$, que acuñó el concepto de arte urbano para designar a los distintos sistemas de proyección y realización planificada de la ciudad a través del tiempo. Como historiador del arte, entendía la ciudad como un continuo espacio-temporal, como el resultado de la evolución de las formas urbanas, en el campo de lo planificado. No obstante, en la actualidad ésta no es la única acepción, otra modalidad de arte urbano o callejero, con orígenes ancestrales pero de implementación tardía ha sido objeto de representación informal en la ciudad moderna, el Graffiti. Expresión gráfica que utiliza el entorno urbano como lienzo, y aprovecha el grado de alta exposición que le ofrece el espacio público de la ciudad. Es considerada 
como una forma marginal de cultura pero no por ello inferior en cuanto a sus capacidades expresivas. Es la representación más primaria y reivindicativa del arte urbano, basada en la toma de las paredes de la ciudad por quién tenga algo que exponer al mundo. Ha sido la técnica más utilizada durante años para expresar la disconformidad ante algunos derechos sesgados.

El urbanismo y/o la planificación es la disciplina que tiene como objeto de estudio la ciudad, y cuyo metier es el de ordenar y gestionar los sistemas urbanos. Acompañando esta definición en apariencia restrictiva, se incluyen formas flexibles y reflexivas de hacer ciudad en la contemporaneidad. Notable es el cambio que se produce en las ciudades desde finales de los años sesenta, mediante un sabio proceso de rectificación de los excesos del urbanismo funcionalista (moderno) poco atento a la cualificación y el potencial cultural de la ciudad.

La contemporaneidad tiene el propósito de crear ciudades vivas, que aparte de ser un medio funcional para el hábitat sean un medio de expresión cultural.

Es en este enfoque de la planificación urbana que el Arte Urbano, como forma de expresión, como proclama política y cultural, adquiere un rol importante. La ciudad se convierte en escaparate y máximo exponente de la libertad de expresión.

El Arte Urbano, por lo tanto puede funcionar como forma de reivindicación política planificada o anárquica, de acuerdo a como se la ejecute. El caso Favela-painting (FP) combina ambos entendimientos, complementa las vacancias de una política pública urbana, y no se encuentra regulada la práctica institucionalmente desde el ámbito público. Por lo tanto el Arte Urbano es un campo que reúne corrientes de actuación muy diferentes en origen, forma e intención.

El Paisaje Urbano es por definición un término complejo dado que lingüísticamente no posee formulación que lo delimite. Por lo pronto existe un supuesto que entiende al paisaje urbano como espacio urbano, el cual de acuerdo a los procesos de crecimiento acontecidos en las últimas décadas, puede categorizarse en tres entornos espaciales: El urbano, el periurbano y el rural. Las características que componen el espacio o paisaje urbano, y a su vez otorgan identidad social son: La densidad de población, homogeneidad en su extensión y una tipología edilicia que lo hace inconfundible. Todos estos atributos los posee la favela brasilera, en cualquiera de sus casos.

Mediante la asociación de estos dos elementos (Arte Urbano + Paisaje Urbano), en función de un proyecto de arte, es que considero que el conocido imaginario del arte urbano del Graffiti es superado. No obstante, sostiene todavía la idea de representar la cultura popular a través de obras que irrumpen en el espacio con cierta ironía, pero el lienzo y el tema de la representación integran a la sociedad no la fragmentan.

El proyecto favela-painting (FP) actúa en complementariedad con políticas públicas de inclusión, que operan a través de la mejora urbana. Cabe aclarar que en la región Latinoamericana indicadores estadísticos, censales y otros relevados por organismos internacionales, han demostrado desde finales de la década de los 80 ', una tendencia creciente de la pobreza e informalidad urbana, cuestión que propicio procesos de exclusión en el acceso a la vivienda propia. Este aspecto en sistemas capitalistas con gobiernos democráticos que sustentan la producción urbana en base a la propiedad privada del suelo, dió origen a procesos de inequidad y desigualdad; que por ende plantearon un problema de crecimiento urbano. 
América Latina posee una vocación territorial urbana, en donde el $80 \%$ de la población reside en estos espacios. La relación que se plantea entre los indicadores de pobreza y los de informalidad demuestra que aún mitigando la pobreza, la informalidad supera los valores de este último indicador, demostrando casos donde existen cantidad de habitantes que han superado la línea de pobreza pero continúan habitando en la informalidad. Por lo tanto esto es un modo de crecimiento que persiste en el tiempo, sostenido por la falta de acceso a la vivienda formal. La retracción del estado neoliberal junto a la merma en el mercado del empleo, contribuyó a un crecimiento de la ocupación del suelo de modo informal y espontáneo en las ciudades cabeceras en busca de oportunidad y acceso a la ciudad, ya sea dentro de los límites urbanos o en sus áreas metropolitanas.

Un valor que posee el caso Favela-painting (FP) es la idea de hacer arte colectivo. El FP es un colectivo artístico que comparte ideologías y actúa en contextos socio-territoriales de desigualdad. En este marco de colectividad incluye avances en cuestiones de género, tal como las primeras arquitectas de la Bauhaus ${ }^{12}$ se motivaron por el estudio de la arquitectura debido a la falta de viviendas para la habitación social en conjunto una vez transcurrida la primera guerra mundial (Hervás y Heras, 2015), el FP nucleó en la acción a mujeres y varones que poseen mismas motivaciones, y donde las condiciones precarias del hábitat son objeto de estudio y transformación.

El proyecto Favela-painting se define como un proyecto de arte comunitario para el cambio social, fue creado en 2005 cuando el colectivo artístico haase $h a h n$, conformado inicialmente por Jeroen Koolhaas and Dre Urhahn, realizan su primer obra para la difusión de la cultura popular y urbana del Hip Hop brasilera. Experiencia que luego prosperó en otras intervenciones de carácter espacial urbano y las cuales consolidaron al colectivo artístico. Bajo una figura de Fundación ${ }^{13}$, que estos mismos artistas han creado, implementan capacidades para autogestión, y pueden reunir los recursos para financiar las intervenciones. Mediante su accionar se pretende construir puentes de cooperación entre el arte comunitario, la planificación urbana ${ }^{14} \mathrm{y}$ el diseño social.

\section{El arte como Proyecto Urbano}

Los proyectos de este colectivo de artistas ofrecen la posibilidad a residentes de los enclaves informales de actuar en conjunto con la finalidad de mejorar las condiciones en las que viven. A través de la Fundación Favela-painting se obtienen los recursos financieros y de infraestructura logística para llevar a cabo los proyectos.

El proyecto inicia en el año 2005 cuando el artista Jeroen Kollhass ${ }^{15}$ arriba a Brasil para filmar un video documental sobre la cultura del hip hop en la ciudad de San Pablo y en Rio de Janeiro. Producto que sería financiado mediante un premio que obtuvo en el Black Soil Film Festival de Rotterdam. El Video expuso al mundo la cultura urbana del hip hop brasilero, siendo difundido por la cadena MTV en Holanda y Brasil. En esta primera experiencia Jeroen invita a Dre Urhahn ${ }^{16}$ a acompañarlo y a colaborar en el documental "Firmeza Total". En el año 2007 otra obra comienza a consolidar la metodología de intervención que luego será el sello este colectivo artístico. El producto fue un mural que representaba a un niño volando un cometa. 

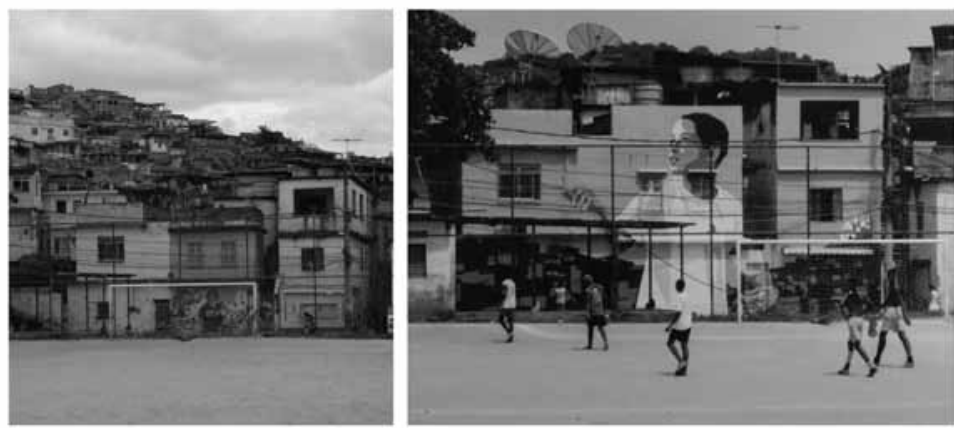

Figura 1. "Boy With a Kite", 2007 FP, Vila Cruzeiro, RJ, www.favelapainting.com/ BOY-WITH-KITE-FP

La obra ocupa la medianera de tres casas precarias que daban al centro de una cancha de fútbol. Para realizar esta pintura, se planteó a los habitantes de las viviendas tres alternativas diferentes, la del niño quedó como la elegida, llamándose entonces el proyecto "Boy with a kite". El tiempo que demoró el mural fueron dos meses, los cuales fueron interrumpidos por actos de violencia, vandalismo y encuentros violentos con la autoridad local. Una vez terminado en los años subsiguientes el mural fue visibilizador de la conflictividad social de la favela, siendo víctima de disparos e impactos de balas en todo el dibujo. Estos impactos originaron que el mural comenzara a deteriorarse, en el año 2012 comenzó el proyecto de restauración.

En 2008 inician un proyecto que involucra la mejora de la calidad del espacio público, obra llamada "Rio Cruzeiro". El espacio a transformar inicialmente era una obra de infraestructura en la favela Vila Cruzeiro, en la calle Santa Helena en Río de Janeiro, misma favela en donde estaba el mural de la obra anterior. Este espacio público era un espacio de accesibilidad peatonal, en donde la ladera de un morro contenía escaleras y una obra de impermeabilización de superficie en hormigón, para evitar desmoronamientos. Por debajo de esta estructura de concreto se diseñaron canales de escurrimiento pluviales. En alusión a este componente subterráneo, y atraídos por la superficie de concreto, el FP convoca a un tatuador de Rotterdam para que diseñe un río de peces Koi.
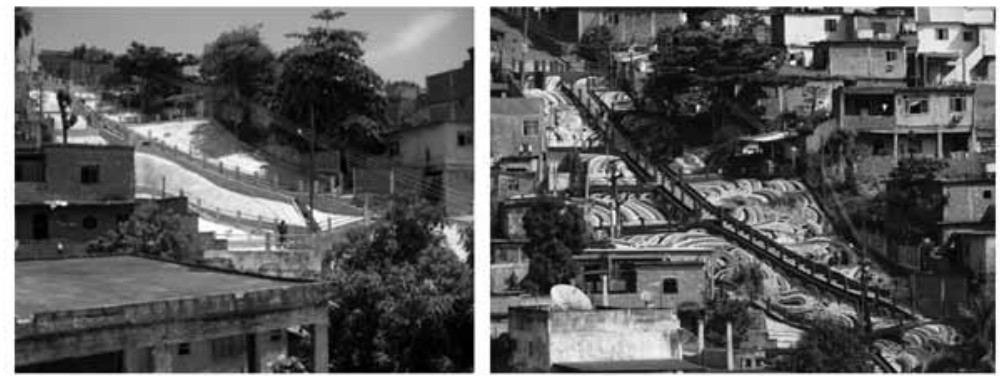

Figura 2. "Rio Cruzeiro", 2008 FP, Vila Cruzeiro, Calle Santa Helena, RJ, www. favelapainting.com/ RIO-CRUZEIRO-FP 
El trabajo llevó ocho meses, para la concreción se convocó mano de obra local y se la capacitó en todas las instancias del proceso desde el traspaso del diseño al concreto, la mezcla de los colores y la organización logística en torno a la paga de salarios y acopio de materiales. Los vecinos colaboraron con espacios para el guardado de materiales y para la preparación de cada almuerzo. A lo largo del proceso se tuvo que lidiar con encuentros armados con la policía local y la gendarmería, sucesos cotidianos en las favelas de Rio de Janeiro, en la época de la implementación del programa de la pacificación de las favelas, donde se pretendía controlar la violencia de las favelas mediante instalaciones de control policial dentro de las favelas. Con miras al mundial del año 2014, hubo un período de aparente tranquilidad desde 2008 hasta esa fecha. Luego, la crisis económica que afrontó el Estado de Río de Janeiro llevo a que el programa agonizara y la criminalidad creciera aún más. El día de la inauguración hubo negociaciones con las autoridades locales y la gendarmería para que no hubiese ningún tipo de encuentro armado. Paralelamente en Holanda se organizo un fiesta que acompaño la inauguración de este espacio, el cual fue televisado por multimedios brasileros.

Al cabo de unos años la intervención sucumbió a los factores climáticos y de otros usos. La intemperie y la lluvia, junto al uso de las rampas por los niños para deslizarse, provocó que la pintura se desmoronase en partes. Es a partir de este momento que se piensa en un modo de restauración, proceso en el cual la mano de obra femenina entra en acción. En el 2018 se repuso todo el dibujo con azulejos de colores, los cuales fueron colocados por las mujeres que vivían en las casas del barrio Santa Helena. Mediante las lecciones aprendidas que esta intervención deja se comienza a involucrar la mejora de la calidad habitacional de las viviendas que bordeaban la intervención. Las casas linderas a la fueron mejoradas, ampliando la escala de actuación de la obra original.

Figura 3. "Santa Helena", 2018 FP, Vila Cruzeiro, Calle Santa Helena, RJ, www.favelapainting.com/ RIO-CRUZEIRO-FP

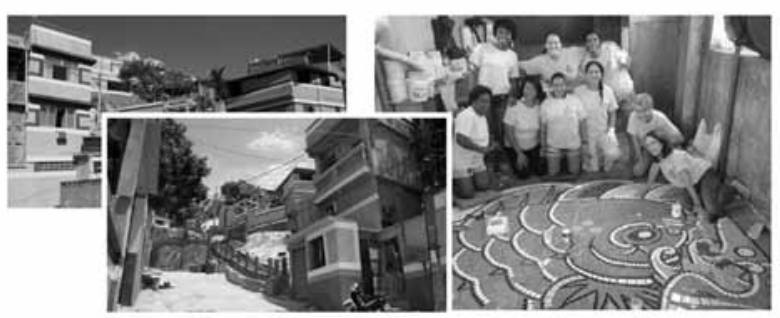

Es en el año 2010 cuando el Favela-painting aborda la escala urbana por primera vez, en la localización conocida como Praca Cantao en la zona sur de la ciudad de Río de Janeiro en la favela de Santa Marta. La situación demuestra el típico contraste entre la ciudad informal y la formal, en donde la primera ocupa las laderas de los morros que exhiben esta configuración espontanea de ciudad. El espacio urbano a intervenir fue compuesto por las viviendas que daban a un espacio público interno de la favela alcanzando $7000 \mathrm{~m} 2 \mathrm{de}$ 
superficie e incorporando a 34 viviendas en la obra. El proyecto contó con capacitación de trabajadores locales para llevar a cabo la obra, la cual con 25 empleados se culminó en un solo mes de trabajo.

Lo destacable de esta propuesta es que antes de realizar la intervención se da terminación constructiva a las paredes exteriores de las casas, impermeabilizándolas e introduciendo mejoras en la calidad habitacional, y posibilitando una mayor vida útil del trabajo de pintura en los paramentos exteriores.

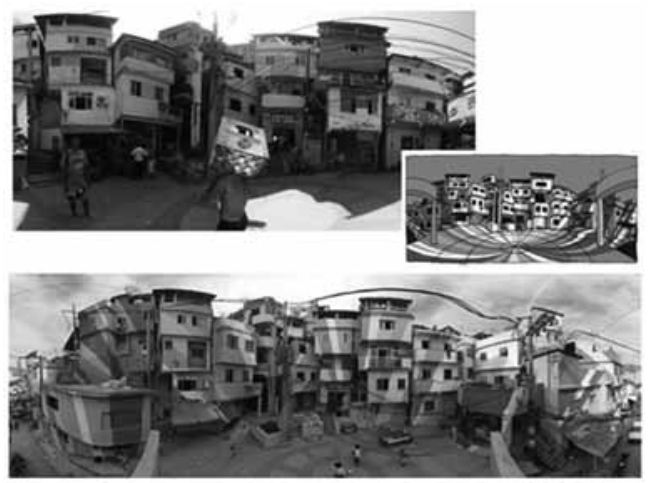

Figura 4. "Praca Cantao", 2010 FP, Santa Marta, Calle Santa Helena, RJ, www.favelapainting.com/ PRACA-CANTAO-FP

La experiencia basada en el arte comunitario para el cambio social ha replicado a través de este colectivo en varios países de América (USA, Haití) y Europa (Grecia, Alemania y Holanda $)^{17}$. Actualmente se están reuniendo fondos para llevar a cabo el proyecto de mayor envergadura, pintar la favela de Vila Cruzeiro en forma completa. Este proyecto es el que llama la atención desde el ámbito de investigación marco de este escrito, como producto artístico que fusiona el campo de la planificación urbana con el del arte.

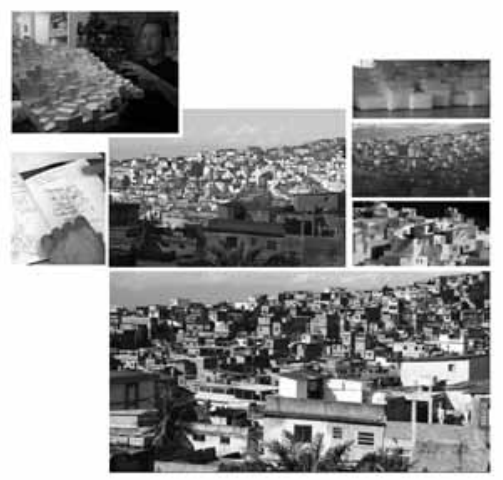

Figura 5: "Proyecto Favela de Vila Cruzeiro", 2018 FP, RJ, www.favelapainting.com/ 
Sobre este Proyecto formulado pero no concretado aún, es donde encuentran espacio las cuestiones teórico-metodológicas que se han explicitado en puntos anteriores. La cooperación y las convenciones posibilitarían que mediante la técnica del cubismo analítico una favela se unifique su imagen de acuerdo a un modo de expresión. Superando al momento la escala de actuación de este colectivo artístico.

Un cuerpo importante de lecciones aprendidas daría respaldo a la intervención. Conocer cómo proteger las obras con técnicas de mayor durabilidad, conocer que en la ejecución propia del proyecto se deben articular intereses de diversos actores sociales para que los trabajos no sean objeto de agresión, y por sobre todo reconocer y no abandonar el compromiso de intervenir en el paisaje urbano. En todos los casos los trabajos han requerido por diversas cuestiones de mantenimientos, que siempre se han implementado. Estos procesos de mantenimiento fueron la fuente del aprendizaje para mejorar el proyecto subsiguiente. Cada nuevo proyecto aumenta la escala e incorpora lecciones aprendidas de forma genuina.

\section{Conclusiones}

La relevancia del tema se denota con un aumento en el gasto público destinado a políticas sociales en la región y en el mundo a partir del año 2005. Gasto que en Sudamérica se mantuvo estable hasta finales del 2013 desde la esfera pública. Las discontinuidades coyunturales junto a sucesivas crisis económicas hacen difícil poder continuar manteniendo el estándar de intervención de los primeros proyectos. A pesar de ello, está instalado dentro de la gestión pública para el desarrollo urbano, que la informalidad es materia de intervención urbana. Queda por definir e integrar conceptos sobre cómo se hace, y que visión deseada (futura) posee esta actuación. Cabe destacar que ante la desaceleración de las políticas de estado, otras iniciativas promovidas por actores sociales de la sociedad civil y/u otros agentes de desarrollo aún sostienen el compromiso de actuación en áreas de vulnerabilidad.

La aspiración a la construcción colectiva del territorio en los actuales contextos de segregación y desigualdad, en Latinoamérica y en el mundo, encuentra desafíos, los cuales se acentúan debido a la todavía distante relación entre los sectores vulnerables de la sociedad y el estado. No obstante, es posible encontrar estrategias de acercamiento, el caso presentado es una de ellas. Este colectivo artístico comprende que la pobreza no es un fenómeno aislado (o "marginal") sino que se reproduce simultáneamente con la riqueza, en el marco global de la reproducción de las relaciones sociales. Y por ello, habilita a un análisis acerca de qué manera se articulan las estrategias de las familias pobres con otras estrategias desplegadas por agentes y/o instituciones que ocupan otras posiciones en el espacio social (Gutiérrez, 2004).

Vinculando las cuestiones teórico-metodológicas de la cooperación y las convenciones, en ámbitos re-emergentes de aplicación de las vanguardias, es donde las lógicas proyectuales de intervención urbanística desarrolladas bajo la perspectiva del Derecho a la Ciudad pueden incurrir en innovaciones históricas ${ }^{18}$, sociológicas ${ }^{19}$ y estéticas ${ }^{20}$ en el ámbito del desarrollo urbano. Tres innovaciones de naturaleza diferente explican en gran medida 
lo inquietante de estas intervenciones ante el ojo analítico del planificador urbano y del espectador. El estado ha sido el promotor de iniciativas de mejora cualitativas en torno a la calidad de vida actuando en el espacio público y dotando de infraestructuras básicas, pero la intervención artística ha logrado alcanzar un proceso de transformación completo, actuando en la mejora cuantitativa de la condición edilicia de las viviendas populares, o sea en el espacio privado. Cabe referenciar, que para que esto sea posible es necesario implementar acciones de desarrollo comunitario y sustentable, mediante una planificación participativa. Esta medida es una política de inclusión en la construcción de consensos locales (comunitarios) y un modo de construir ciudad con un fuerte apego y apropiación. A tal fin, el Estado como actor al que le interesan los fines por los que se moviliza la gente para la acción colectiva, debe permitir la producción de objetos que constituyen el arte, así como proporcionar una cuota de apoyo (Becker, 2008).

La interpelación que plantea la obra Favela-painting en el paisaje urbano informal, radica en comprender que la pintura ( $u$ otro modo de arte) no da ninguna respuesta, sino que plantea nuevas preguntas, genera nuevas curiosidades. El arte interroga, pregunta a través de su concreción ante el espectador, que apreciación merece. Plantea reclamos y nuevas proclamas.

$\mathrm{Al}$ arte se le han atribuido diferentes funciones a través de la historia, desde ser un medio de representación de la realidad hasta brindar un puro goce estético. En la contemporaneidad imperan las obras que buscan una crítica social. En donde nos pregunta a nosotros mismos quienes somos como sociedad en la contemporaneidad, o en todo caso nos recuerda que tipo de sociedad queremos ser. En esta búsqueda se visibilizan problemáticas tales como la relación entre lo personal y lo político.

\section{Notas}

1. Programación científica 2016-2019 SI-FADU-UBA.

2. Directora de proyecto y Marco de inserción del Proyecto de Tesis de Doctorado: "Proyecto Urbano + Infraestructura Urbana como instrumentos para la inclusión”.

3. "Ser y tiempo", 1927.

4. "La Révolution urbaine", 1970.

5. “Teoría de la acción comunicativa”, 1987.

6. HIC, UN Hábitat: I (1976, Vancouver); II (1996, Estambul); III (2016, Quito).

7. Este programa posee antecedentes desde 1980, pero no es sino hasta el nuevo donde consigue apoyo financiero internacional.

8. El proyecto Urbano Integral, en la nómina de casos de estudio Brasil ofrece aporte empírico en torno a este tipo de intervenciones.

9. Braque y Picasso entre 1908 y 1911, practicaron el cubismo analítico como referentes del movimiento. La técnica del facetado fue uno de los principales recursos, donde el espacio se representa por facetas fragmentadas que luego al visualizar la obra en forma completa se unifican dando un sentido conocido al objeto.

10. Si se asocia a la noción militar de combate de las primeras líneas de la formación que respondían a la acción de avanzar para el combate. 
11. Historiador del arte Pierre Lavedan que en 1926 con su Obra ¿Qué es el Urbanismo? define desde el enfoque de la historia que es la práctica del urbanismo y cuáles son sus productos.

12. Revista de la escuela de la Bauhaus $n^{\circ} 2 / 3$ año 1928 , entrevista a varios estudiantes. La estudiante de 23 años Lotte Burckhardt dijo que había llegada allí por el interés demostrado por la institución ante: "el manejo de la construcción en tanto que se ocupa de la necesidad residencial ante la falta de viviendas para la gente y las condiciones sociales en su conjunto". 13. Este programa fue apoyado, en parte, por fondos públicos de los Servicios Culturales Neerlandeses. Este proyecto ha recibido financiación a través de una subvención de la Fundación Netherland-America, la Fundación Mondrian, Amsterdam, y la Fundación Holandesa de Artes Visuales, Diseño y Arquitectura (Fonds BKVB). La recepción de apertura fue generosamente financiada por Melissa Shoes.

14. El vínculo entre la intervención del FP y del Programa de Urbanización de Asentamientos Populares se da a través del Puesto de Orientación Urbanística y Social (POSTO), inserto en dicho programa, el cual articula acciones sociales comunitarias dentro de las favelas intervenidas.

15. Jeroen Koolhaas (Rotterdam, 1977) estudió diseño gráfico en la Design Academy en Eindhoven y ha trabajado como diseñador e ilustrador audiovisual freelance para la revista New Yorker desde su graduación. www.jeruniverse.com

16. Dre Urhahn (Amsterdam, 1973) ha trabajado como periodista, redactor y director de arte y ha establecido exitosas compañías especializadas en diferentes campos, desde la gestión de eventos hasta la producción televisiva.

17. En Alemania estos dos artistas principales del favela-painting, participan del PhillyPainting (2012), en USA en Miami en Wynwood Walls (2014), en Holanda y Grecia mejoran asentamientos de refugiados (2016-2018), en Haití actuaron convocados por otra organización para mejorar las condiciones del hábitat de Vila Rosa en Puerto Príncipe (2016-2018) asentamiento deteriorado por el terremoto de 2010, en el Caribe intervinieron en Curacao(2014-2016) fundando una academia que capacite mano de obra local.

18. Históricas porque demuestra novedades en las historia de ese campo y supera criterios establecidos.

19. Sociológicas por que resuelve problemas, paradojas o anomalías reconocidas como tales por la comunidad y a su vez, plantea nuevos problemas.

20. Estéticas por que necesariamente requiere interpretación.

\section{Referencias Bibliográficas}

Becker, H. (2008). "Mundos de arte y actividad colectiva", en Los mundos del arte, Buenos Aires, Universidad Nacional de Quilmes. Disponible en: https://drive.google.com/ file/d/0Bw0mBdvFuWu4N3pXak4tT25FWGs/view?usp=sharing

Cappuccio, S. y Mignaqui, I. (2015). La política de urbanización de villas y asentamientos precarios en la Cuenca Matanza - Riachuelo: la consolidación de los territorios de la desigualdad. En XXIX Jornadas de Investigación y XI Encuentro Regional, SI+TER, FADU - UBA. Buenos Aires. ISBN 9789502915777. 
Gutierrez, A. (2004a). “La teoría de Bourdieu en la explicación y comprensión del fenómeno de la pobreza urbana”. En: Martín Criado, E. Alonso, L. y Moreno Pestaña, J. (Comp.). Pierre Bourdieu: las herramientas del sociólogo. (pp. 255-280). Madrid: Fundamentos.

Habermas, J. (1987). “Teoría de la acción comunicativa” T. I, Madrid: Ed. Taurus.

Heidegger, M. (1927). Ser y Tiempo. SCM Press; SUNY Press; HarperCollins.

Hervás Y Heras, J. (2015). "La Bauhaus de Weimar. Ellos (y ellas) en pos de una meta común: la arquitectura", Revista Europea en Investigación de Arquitectura, n³. Disponible en: http://oa.upm.es/34242/1/JOSENIA_HERVAS_Y_HERAS_1.pdf

International Habitat Coalition (--) Agenda HABITAT I, 1976; HABITAT II, 1996; HABITAT III, 2016.

Lavedan, P. (1926). “¿Qu'est-ce que l'urbanisme?”. Introduction à l'histoire de l'urbanisme, Paris: Laurens.

Lefebvre, H. (1970). La Révolution urbaine, Paris: Gallimard [traducción castellano (1972): La Revolución Urbana, Madrid: Alianza Editorial.

Longoni, A. y Davis, F. (2009). "Las vanguardias, neovanguardias, posvanguardias: Cartografías de un debate", en Katatay. Revista crítica de literatura latinoamericana, $\mathrm{N}^{\circ} 7$, septiembre de 2009. Disponible en: https://drive.google.com/file/ $\mathrm{d} / 0 \mathrm{Bw} 0 \mathrm{mBdvFuWu} 4 \mathrm{Yk} 5 \mathrm{LSEZNZmFfX0E/view?usp=sharing}$

Souza Pereira, L. A. (2010.) "O programa Favela-Barrio: Mais do mesmo? Quais as posibilidades para a superacao dos "problemas" existentes na cidade do rio de janeiro". En Scripta Nova, Universidad de Barcelona, ISSN: 1138-9788. Vol. XIV, núm. 331 (54), 1 de agosto de 2010.

\begin{abstract}
The current urban art not only intends to engage in a dialogue with society, it also proposes to transform the city. A model case on the use of art as an auditor of the urban landscape, which is presented in this writing, is the Favela-painting project, experience which has strengthened and expanded the powers of urban art, linking methods and expressions of the artistic field with urban improvement objectives.

Motivated by social inequality, two Dutch artists decide to reinterpret the canvas, finding in the precarious facades of popular housing that possible means of expression. The analysis of this experience, from the urban planning approach, claims the informal space through art, because the improvements achieved on the urban landscape and the constructive quality of the popular housing are remarkable.

Social conflict is addressed in an alternative way, empowering the population with art as a vehicle for appropriation, cooperation, training and self-management. This initiative has coincided with other actions on urban informality promoted by the state. Neighborhood improvement programs are overlap with the case in question, proposing in the mixture of these fields new forms of relationship between art and politics.
\end{abstract}

Keywords: Urban art - cooperation - inequalities - intervention - urban landscape. 
Resumo: A arte urbana atual não pretende apenas dialogar com a sociedade, mas também propõe transformar a cidade. Um caso-modelo sobre o uso da arte como auditor da paisagem urbana, apresentado neste artigo, é o projeto de pintura em favelas, experiência que fortaleceu e ampliou os poderes da arte urbana, vinculando métodos e expressões do campo artístico aos objetivos de melhoria urbana.

Motivado pela desigualdade social, dois artistas holandeses decidem reinterpretar a tela, encontrando nas precárias fachadas da habitação popular os possíveis meios de expressão. A análise dessa experiência, a partir da abordagem do planejamento urbano, aborda o espaço informal através da arte, uma vez que as melhorias alcançadas na paisagem urbana e a qualidade construtiva da habitação popular são notáveis.

O conflito social é abordado de forma alternativa, capacitando a população com a arte como veículo de apropriação, cooperação, capacitação e autogestão. Essa iniciativa coincidiu com outras ações de informalidade urbana promovidas pelo estado. Programas de melhoria de vizinhança são sobrepostos ao caso em questão, propondo na mistura desses campos novas formas de relacionamento entre arte e política.

Palavras chave: Arte urbana - cooperação - desigualdade - intervenção - paisagem urbana.

[Las traducciones de los abstracts fueron supervisadas por el autor de cada artículo] 